\title{
Morar na rua: Fluxos e Fronteiras ${ }^{148}$
}

\section{Paula Rochlitz Quintão ${ }^{149}$}

“(...) o sentimento de busca, o estranhamento de um mundo onde sentir-se estrangeiro é a regra, as perdas, os encontros, e o atar e desatar dos nós que se formam ao se navegar nas águas incertas da existência humana."

Os nós do exílio

Juliana Sartorelo Bittencourt

O presente trabalho não poderia deixar de mencionar o panorama atual de pandemia da Covid-19. Tendo participado de quase todos os "Censos de População Rua" desde 2000, quando foi feita a primeira "Contagem do Número de Moradores de Rua da Cidade de São Paulo", é impossível não notar o vultoso aumento da população de rua desde o início desta pandemia. E não só nas cidades brasileiras. Mas partiremos da análise do caso de São Paulo, como paradigma da metrópole brasileira.

De acordo o último censo realizado no final do ano passado (2019) pela Prefeitura de São Paulo, a "População em situação de rua" (denominação oficialmente utilizada no Brasil) na cidade saltou de aproximadamente $16 \mathrm{mil}$ pessoas, em 2015, para mais de 24 mil pessoas em 2019 - um aumento de 53\% no período. O número é o maior desde que este levantamento é feito. Há 20 anos, menos de 9 mil pessoas "viviam na rua" ou "passavam parte do dia na rua". Ao mesmo tempo em que a população paulistana como um todo cresceu 1,7\%, a população de rua de São Paulo aumentou 180\%: uma escala cem vezes maior. O último Censo foi executado em outubro a dezembro do ano passado (2019). Apenas dois meses depois, a Covid-19 chegou ao Brasil. Falar sobre população de rua neste momento é, portanto, urgente.

\footnotetext{
${ }_{148}$ Trabalho apresentado na mesa "Cidade em movimento: fronteiras e travessias" no II Simpósio Bienal SBPSP "Fronteiras da Psicanálise: a clínica em movimento" no dia 29 de agosto de 2020. Derivado da dissertação de Mestrado em Arquitetura e Urbanismo da autora: "Morar na rua: há projeto possível?”, com orientação de Prof. Dr. Carlos Roberto Zibel Costa, defendida na Faculdade de Arquitetura e Urbanismo da Universidade de São Paulo, FAUUSP, em 2012.

${ }^{149}$ Mestre (2012) em arquitetura e urbanismo pela FAU-USP, integrante da Rede Pop Rua - Rede Brasileira de Pesquisadores sobre População em Situação de Rua, coordenado pela Profa. Dra. Silvia Maria Schor.
} 


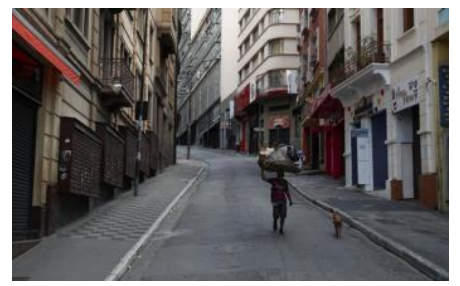

Morador de rua desce por rua vazia no primeiro dia de quarentena decretada pelo Governo do Estado de São Paulo devido à pandemia do Coronavírus.

Foto: Amanda Perobelli / Reuters 24.03.2020

De caracterização muito diversa, esta população abrange desempregados, trabalhadores informais, ex-presidiários, pessoas sem moradia fixa, imigrantes, e outros. A coleta de materiais recicláveis é a maior fonte de renda. Embora a grande maioria seja adulta e do sexo masculino, houve um aumento no número de pessoas que se autodeclararam trans. Com média de idade entre 31 e 49 anos, "não-branca" (negros e pardos), não se limita a este perfil apenas: contempla também famílias, e menores em situação de rua. Trata-se, portanto, de uma população heterogênea.

O modo como o tema é tratado hoje, na maioria das grandes metrópoles ao redor do globo, tem como enfoque das ações e políticas públicas a tentativa de retirada dessas pessoas do espaço urbano. Mas a análise da "população em situação de rua" mostra que há pessoas que desejam sair dessa situação condição, portanto, circunstancial, - e outras que continuam / continuarão a habitar as ruas por motivos variados - condição, portanto, permanente.

Uma variável importante refere-se ao tempo de rua, uma vez que a permanência na rua altera o comportamento das pessoas, suas percepções, e cria um tipo de sociabilização que torna a saída das ruas cada vez mais difícili5o. Dados do Censo (2009) mostram que $25 \%$ da população mora nas ruas há menos de 1 ano. Por outra parte, 25\% permanece nas ruas há mais de 10 anos - ou seja, quanto maior o tempo de rua, mais improvável as possibilidades de saída desta.

As mesmas políticas públicas que definem como morador de rua aquele que "por contingência temporária ou permanente, pernoita em logradouros públicos, (...)", parecem não contemplar esta parcela que estará sempre nessa situação seja por impossibilidade de saída desta condição, seja por permanência prolongada, por resistência ou mesmo por renovação do contingente (no sentido de que, mesmo com a saída daquele indivíduo, outro entrará no seu lugar). Haverá, portanto, continuadamente, uma parcela flutuante que, efetivamente, habitará as ruas.

${ }^{150}$ FIPE, 2009/2010, arquivo 3, p.6. 
As estruturas urbanísticas voltadas a esse grupo são escassas, pouco eficazes e parecem partir do pressuposto de que há um desejo em todos moradores de deixar de morar nas ruas. O que há, na realidade, é o desejo da sociedade: de retirada destes indivíduos do cenário. Espera-se uma solução definitiva, simples (e simplista): prevalece a ideia de que este fenômeno tem causas exclusiva ou simplesmente concretas (pandemia, perda de emprego, de casa, ausência de vínculos familiares, desigualdade social, fragilidades psíquicas, drogas, entre outros), que poderiam ser resolvidas com ações pontuais: provendo a casa, o emprego, ou reestabelecendo os laços familiares, por exemplo, retiraríamos esses indivíduos da rua e, portanto, em teoria, não haveria mais moradores de rua no cenário das nossas cidades. Esta noção é, no entanto, equivocada: são diversas as facetas do morador de rua, diferentes em cada cultura na qual se insere, e que variam de indivíduo para indivíduo. O morador de rua deveria ser tratado não como indivíduo apartado da sociedade, mas dentro da cultura na qual ele se insere, portanto, dentro de um pensamento complexo, no sentido de unir saberes, "tecendojunto" (E. MORIN).

No presente cenário, o aumento da população que está nas ruas não voltará ao "número normal" (número pré-COVID-19 de "Pessoas em situação de rua", ou seja, do Censo de dezembro/2019), quando a pandemia acabar. Mais improvável ainda é que este número regrida a zero, ou seja, que não existam mais pessoas morando nas ruas. E não precisamos de muita ciência para prever esta situação de não-retorno ao número inicial, antes da crise... O resultado é o que vemos por toda parte: estes indivíduos continuam a habitar os espaços da cidade e, pior, sem qualquer qualidade. Apenas sobrevivendo.

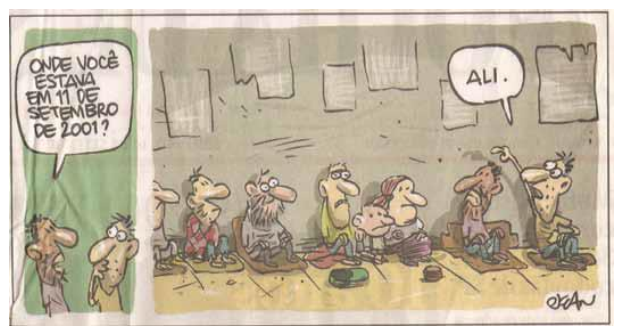

Jean Galvão. Folha UOL, 11 Set. 2010

Soluções homogeneizantes, portanto, resolvem apenas parcialmente o problema, pois desprezam o cerne da problemática: a complexidade que é inerente à natureza da vida humana, principalmente nos grandes centros urbanos. Se há possibilidade de outras intervenções na contemporaneidade, é preciso aceitar trabalhar com esta contingência. 
Se, então, para uma parte dessa população, a resposta adequada seria a oferta aos meios que proporcionem sua saída das ruas - e, neste caso, o albergamento e outros centros de apoio e acolhida aparecem como possibilidades - o grande e novo desafio diz respeito aos que optam viver nas ruas. Para esses a cidade terá de assumir sua existência no território urbano e, mais que isso, aceitar o seu direito à cidade como inerente a uma cidadania plena, contemporânea.

Projetar para a população de rua inicia-se, portanto, pelo estudo de sua inserção física no tecido urbano (sentido de Localização) e, por fim, do seu espaço imediato, seu entorno, seja ele na rua ou no projeto de seu quarto dentro do abrigo, albergue ou afins (lugar).

Analisaremos aqui a movimentação da população de rua por duas variáveis que são inerentes a sua existência: Fluxos (movimentos) e Fronteiras (limites).

\section{Fluxos:}

Se o que caracteriza o morador de rua é o seu não pertencimento a um local; e se, portanto, sua existência compele à itinerância, não é viável a existência de um local de pernoite fora do seu trajeto a pé.

A questão da mobilidade - como ele se desloca pela cidade - lhes é imprescindível. Para os carrinheiros, este elemento é principal; impossível se deslocar pela cidade com o peso do carrinho, e ir a um local distante para o pernoite. Por isso, muitos dormem na rua, perto de onde já estão. De acordo com a tabela de "Deslocamento durante o dia", da Contagem de 2003 (tab. 5.2, FIPE), para os que pernoitavam nas ruas: a maioria $(38,3 \%)$ permanecia no mesmo distrito, 20\% se deslocavam até distritos vizinhos, 11,2\% até outros distritos, e apenas $1,3 \%$ para outros municípios. Ou seja, a maioria permanecia numa mesma área, e o número de deslocamentos vai diminuindo ao se aumentarem as distâncias percorridas. Para os moradores albergados (tabela 6.8, FIPE, 2003): $36,4 \%$ permaneciam no mesmo distrito, $23,7 \%$ se deslocava até distritos vizinhos, $33,6 \%$ até outros distritos, e apenas 1,9\% até outros municípios. Novamente notase que a maioria permanecia no mesmo distrito ou vizinho, ou seja, deslocamentos pequenos. Mas a alta porcentagem de deslocamentos "até outros distritos" entre a população albergada se deve, aparentemente, ao fato de que a população albergada, em sua maioria, não faz uso dos carrinhos, uma vez que é 
difícil ter albergues com estacionamento para estes. Não sendo essas pessoas, em sua maioria, catadores, fica mais fácil percorrer distâncias maiores. Outro fato aparente pode ser o de que a população albergada, mais do que o local onde "prefere estar", está onde se localizam os albergues ou outras estruturas similares de acolhida, uma vez que estes estruturas de apoio não estão em locais estratégicos da cidade, mas, sim, em “qualquer local disponível”, aleatoriamente. Para os que usam estas estruturas, deslocar-se para o pernoite é a única alternativa: ir onde o albergue está.

Deste modo, ao se propor estruturas de Acolhida ou qualquer outro equipamento para esta população, há de se levar em conta a localização. Deveriam, portanto, estar dentro deste fluxo: no percurso dessas pessoas, no trajeto dos carroceiros - e não fora deles - para que possam efetivamente acessálos.

Por outro lado, se um indivíduo é egresso de um Centro de Atenção Psicossocial (CAPS), para citar um exemplo, depois de um tratamento para transtorno pelo uso de álcool e drogas, ele não pode voltar ao Centro de acolhida ou a qualquer outro local apoio (república, casas de aluguel) que esteja dentro desta área central, ou do fluxo. Neste caso, o apoio tem que estar longe da rota do crack, das drogas, das "biqueiras": ou seja, fora do fluxo. Dentro do fluxo ou fora do fluxo?: Depende do resultado que se pretende obter.

E onde estas pessoas estão?

Não é coincidência que estejam nos distritos mais centrais do Município de São Paulo: concentram-se ao redor dos pontos comerciais que ficam vazios à noite. E estas concentrações têm a ver com a lógica de descartes da metrópole. Como apontado, a grande maioria $(62,1 \%$, FIPE, 2009) dos moradores das ruas, tem como fonte principal de renda a coleta de material reciclável.

Para analisar como se dá a relação entre os locais com maior descarte de materiais, maior volume de resíduos e a concentração de moradores de rua, buscou-se analisar os setores que mais geram descarte e resíduos: os setores secundário (indústrias) e terciário. Foram utilizados os dados do "Censo de população em situação de rua" de 2009/2010151, resultados "por distritos” (FIPE,

${ }^{151}$ Os dados do Censo 2019 (Qualitest/SMADS) ainda não estão disponíveis. 
2009 / 2010), e mapas dos setores secundário e terciário, para verificar a concentração / distribuição dos moradores de rua, em relação a estes setores.

Resumidamente, se sobrepormos as manchas de "Concentração de moradores de rua por distrito" (Mapa 1), e o mapa de "Uso do solo predominante do Município de São Paulo" (Mapa 2): não por acaso, eles são coincidentes (Mapa 3) (ver análise completa em: QUINTAO, P. R. "Morar na rua: há projeto possível?”). Verificou-se que a distribuição espacial desta população não é aleatória: tem relação com a localização dos estabelecimentos comerciais, de serviços, e da indústria, ou seja, se insere tanto na lógica de descartes e geração de resíduos destes locais, quanto na de fluxo de transeuntes, gerados pelas áreas onde se concentram os serviços.

Mapa 1. Concentração de Moradores de rua por Distritos (Município de São Paulo. Dados do Censo 2009)

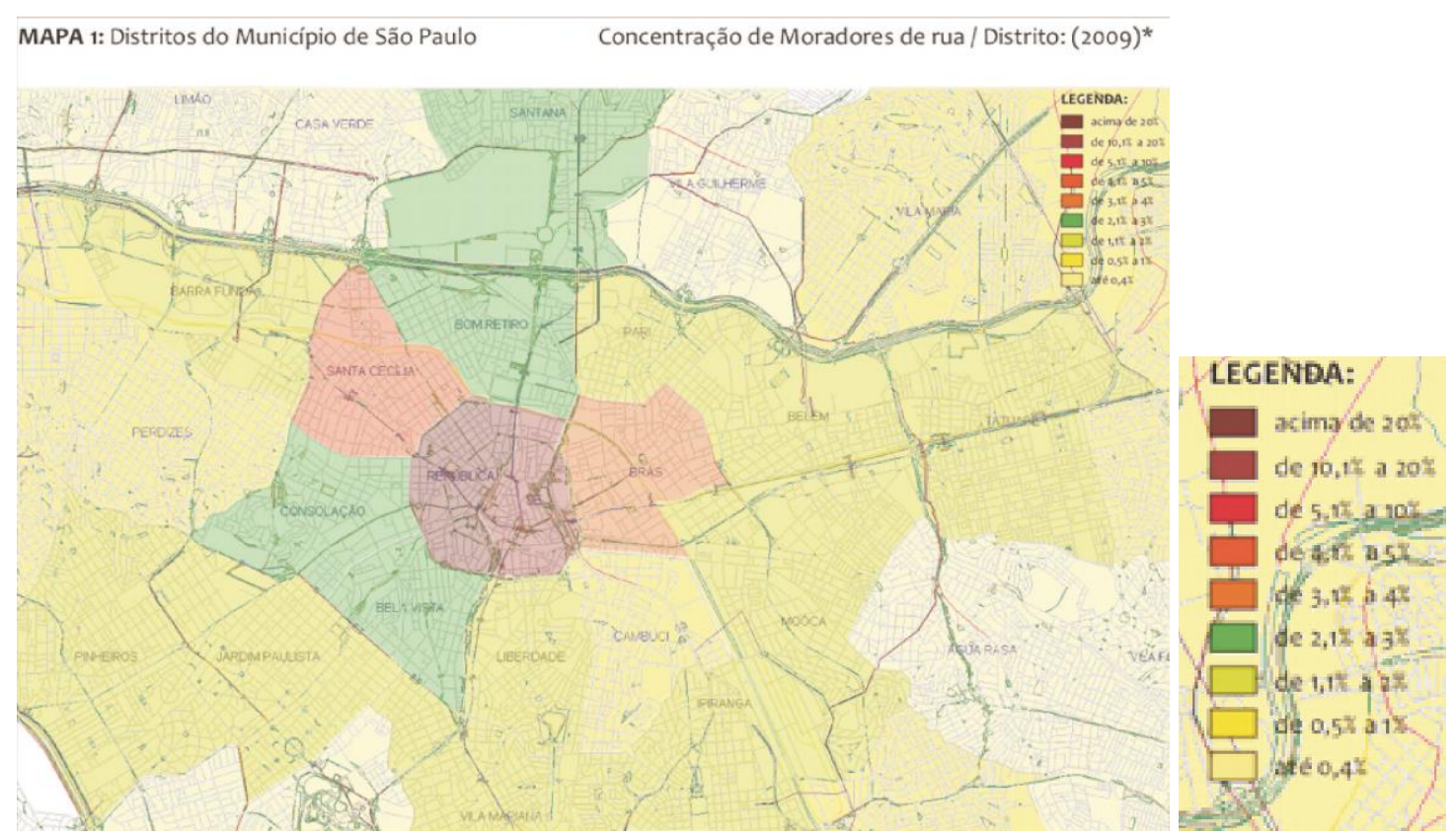




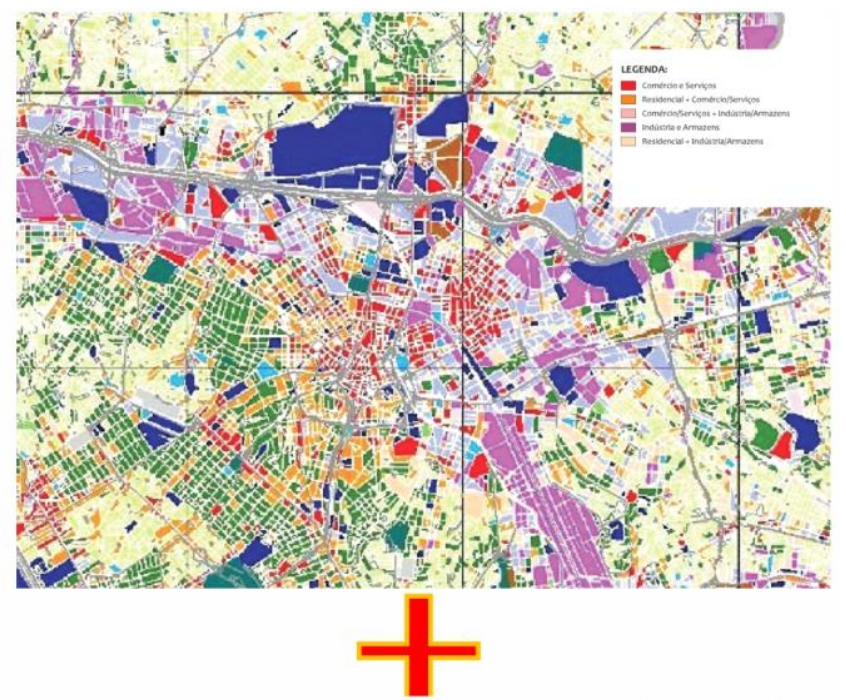

Mapa 1. Concentração de moradores de rua por Distrito (Censo 2009)

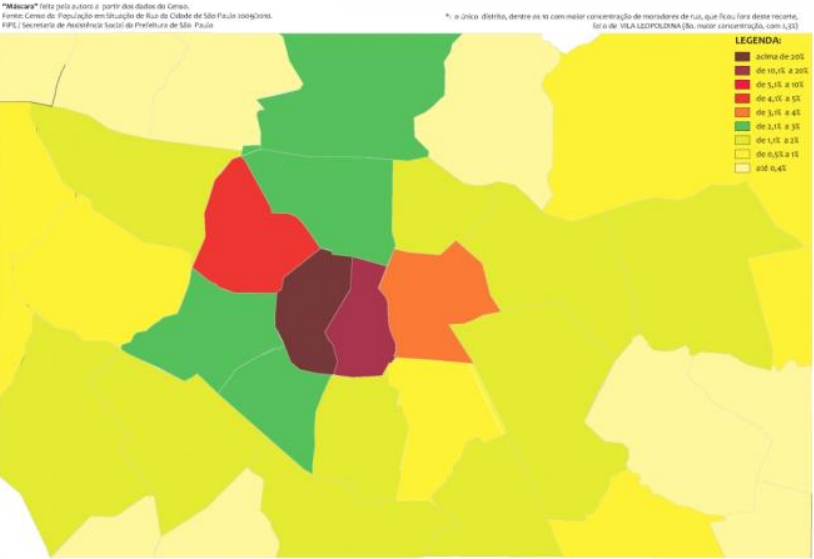

Mapa 3.A: AMPLIAÇÃO da área indicada Mapa 3.B: Justaposição dos Mapas 1 e 2: notar no Mapa 2 Distritos da área central do que áreas COINCIDEM (Distritos da área Município de São Paulo central do Município de São Paulo x Censo 2009)

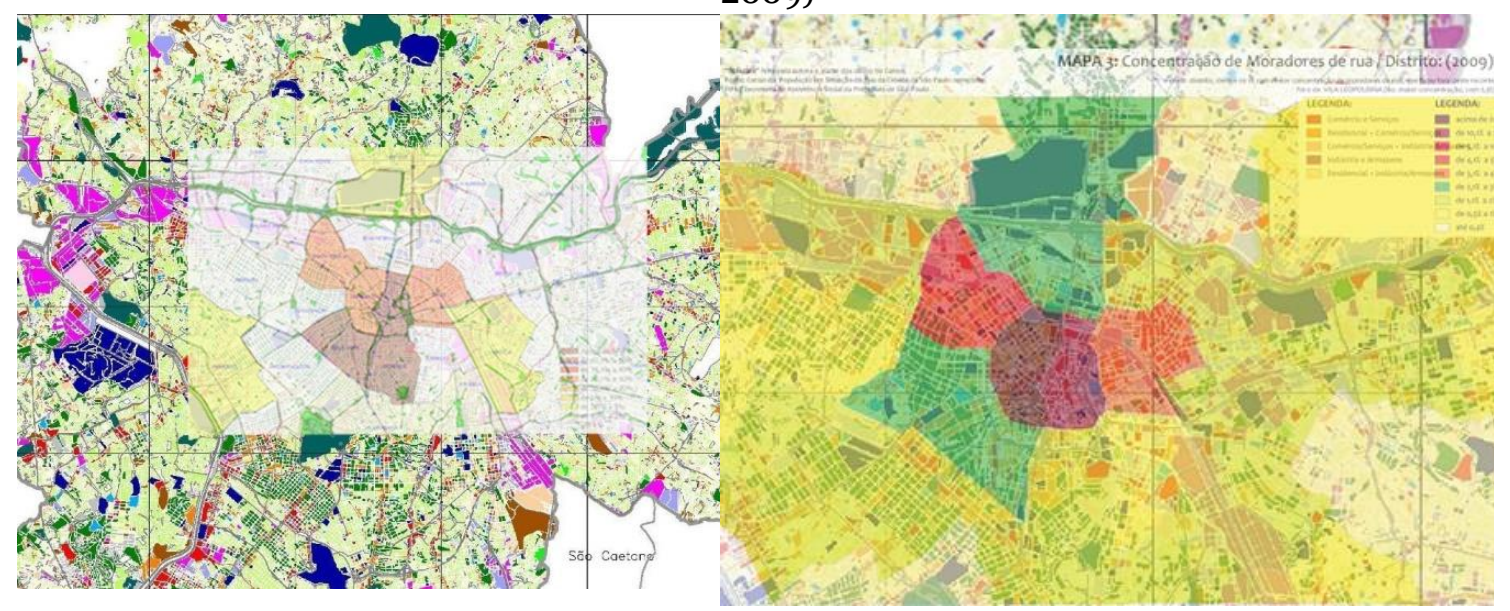




\section{Fronteiras:}

São várias as fronteiras a serem contempladas: fronteiras espaciais (Público / Privado); fronteiras socioeconômicas (Dentro / Fora), e tantas outras.

O morador de rua tem no espaço público o seu espaço de vivência e de sobrevivência. O conflito se inicia aí: para ele o privado e o público se confundem, na medida em que o espaço público é para ele espaço privado, que dele, portanto, depende. No entanto, paradoxalmente, mais do que a qualquer outro cidadão, a ele é negado o direito ao espaço público. A negação se dá por meio da tentativa de isolamento. Na cidade a segregação sócio-espacial se faz de ambos os lados: o confinamento se realiza tanto em locais "qualificados" (por exemplo, nos condomínios fechados) quanto em locais residuais (por exemplo, as favelas). Dados da pesquisa "Origem-Destino" do Rio de Janeiro mostram que 30\% dos deslocamentos são para dentro da própria favela. O espaço oferecido é também uma forma de aprisionamento.

As intervenções nas cidades são intervenções excludentes, que empurram as pessoas para fora da cidade e não para dentro do planejamento urbano. E há diálogo nestas fronteiras?

Neste sentido, a pandemia não cria nada - ela apenas revela: revela as fronteiras que são consequências da desigualdade, revela a ausência do Estado, as fraquezas do sistema de saúde, o crescimento desordenado das cidades, a falta de infraestrutura.

Falta de estrutura urbana para os moradores para os moradores de rua, que fez que com que a Prefeitura instalasse, às pressas, máquinas de lavar roupa nas ruas, durante a quarentena.

Foto: Alfredo Henrique, Folha SP

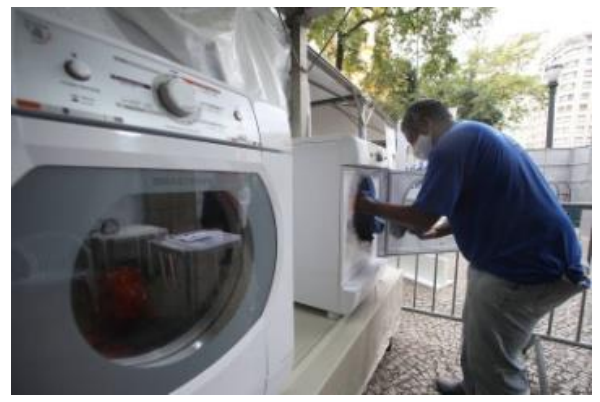

Falta de estrutura urbana para os moradores para os moradores de rua, que fez que com que a Prefeitura instalasse, às pressas, máquinas de lavar roupa nas ruas, durante a quarentena. 
Uso o termo "omitidos", que parece representar bem este grupo: (Dic. Aurélio): "Omitir": não mencionar; deixar em esquecimento; preterir, postergar; não tomar conhecimento de.

É possível perceber então que há um contingente que sempre habitará o espaço público, mesmo se lhe fossem oferecidas oportunidades para sair dele. É premente, portanto, tratar do caso não mais do "morador de rua" (o indivíduo), mas do "morar na rua" (o ato de habitar as ruas das cidades; a relação entre indivíduo e espaço urbano), admitindo os moradores de rua como parte integrante do cenário urbano, e apontando, portanto, para a necessidade de inclú́-los nos projetos do espaço urbano. Não apenas a pessoa "em situação de rua", o homeless (aquele que está temporariamente nas ruas), mas o "morador da rua”, o street-dweller (aquele que estará permanentemente nela).

Entender estas localidades, a distribuição destes indivíduos dentro do território urbano, - que se relacionam tanto com a infraestrutura na metrópole, quanto com os meios de sobrevivência - é premissa para qualquer projeto urbano.

E deve partir tanto na escala MACRO, a do planejamento urbano, e das localizações estratégicas destes "pontos de apoio", quanto da escala mais pontual (escala MICRO), que é o projeto de cada equipamento - sejam eles construídos (instalações como albergues, centro-dia, casas de acolhida) ou temporários (estruturas, tendas, equipamentos de apoio ou mobiliário urbano). Apenas a partir destas análises será possível ao arquiteto urbanista projetar, do latim 'projectare': lançar à frente, planejar, propor.

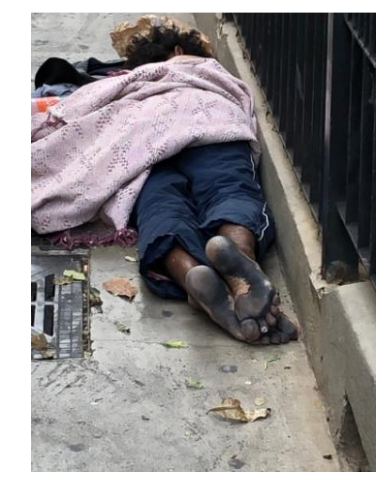

Foto: Paula Rochlitz Quintão

\section{Referências}

COSTA, Carlos Zibel. Além das Formas - Introdução ao pensamento contemporâneo nas artes, no design e na arquitetura. São Paulo: Ed. Annablume, 2010. 
Decreto $\mathrm{N}^{0}$ 7.053, de 23 de Dezembro de 2009: Institui a Política Nacional para a População em Situação de Rua e seu Comitê Intersetorial de Acompanhamento e Monitoramento, e dá outras providências. Brasília / DF.

FIPE - Fundação Instituto de Pesquisas Econômicas e SAS / PMSP - Secretaria de Assistência Social. Primeiro Censo de Moradores de Rua da Cidade de São Paulo, 2000.

. Contagem do Número de Moradores de Rua da Cidade de São Paulo,

2003 .

/ 2010

. Censo da População em Situação de Rua da Cidade de São Paulo 2009

Disponível em:

<http://www.prefeitura.sp.gov.br/cidade/secretarias/assistencia social>

FIPE - Fundação Instituto de Pesquisas Econômicas e SMADS - Secretaria Municipal de Assistência e Desenvolvimento Social, Prefeitura de São Paulo. Censo da População em Situação de Rua da Cidade de São Paulo, 2015 Resultados

Disponível em:

$<$ https://www.prefeitura.sp.gov.br/cidade/secretarias/upload/assistencia soci al/observatorio social/2015/censo/FIPE smads CENSO 2015 coletivafinal.p df

. Censo e Contagem de Crianças e Adolescentes na Cidade de São Paulo. São Paulo, Ago.2007.

Disponível em: <http://pfdc.pgr.mpf.gov.br/atuacao-e-conteudos-deapoio/publicacoes/crianca-e-adolescente/censo-criancaeadolescente-sp>

GUATELLI, Igor. Contaminações constitutivas do espaço urbano: cultura urbana através da intertextualidade e do entre. Arquitextos Vitruvius 94, ano 08 mar.2008. ISSN 1809-6298. [texto parcialmente resultante do trabalho: GUATELLI, Igor. O(s) lugar(es) do entre na arquitetura contemporânea: arquitetura e pós-estruturalismo francês. Tese (Doutorado) - Faculdade de Filosofia, Letras e Ciências Humanas da Universidade de São Paulo, FFLCH-USP, São Paulo, 2005].

Disponível em:

<http://www.vitruvius.com.br/revistas/read/arquitextos/08.094/155>

HABERMAS, Juergen. Arquitetura Moderna e Pós-moderna. in: Dossier Habermas, Revista Novos Estudos CEBRAP, São Paulo, set. 1987.

HANNERZ, Ulf. Fluxos, fronteiras, híbridos: Palavras-chave da antropologia transacional. MANA 3(1), 1997, p.7-39.

Disponível em: <http://www.scielo.br/pdf/mana/v3n1/2454.pdf>

MEYER, Regina M. Prosperi; GROSTEIN, Marta Dora. São Paulo Metrópole. São Paulo: Ed. Universidade de São Paulo: Imprensa Oficial do Estado de São Paulo, 2004.

Ministério do Desenvolvimento Social e Combate à Fome. Secretaria de Avaliação e Gestão da Informação. Meta Instituto de Pesquisa de Opinião. Meta/MDS. Pesquisa nacional sobre a população em situação de rua. Abril. 2008. Disponível em: <www.mds.gov.br/backup/arquivos/sumario executivo pop rua.pdf>

MORIN, Edgar. Os princípios do conhecimento pertinente. In: Os Sete Saberes necessários à Educação do Futuro. Brasília, Cortez Ed. UNESCO, 2000. Cap. II, p.35-46. 
QUALITEST. Censo da População em Situação de Rua. 2019. Disponível em: $<$ https://www.prefeitura.sp.gov.br/cidade/secretarias/assistencia social/obser vatorio social/pesquisas/index.php? $\mathrm{p}=18626>$

QUINTÃO, Paula Rochlitz. Morar na rua: há projeto possível? Dissertação de Mestrado em Arquitetura e Urbanismo da autora: com orientação de Prof. Dr. Carlos Roberto Zibel Costa, defendida na Faculdade de Arquitetura e Urbanismo da Universidade de São Paulo, FAUUSP, 2012.

O sujeito (oculto) e a cidade: A arte de Wodiczko. In: IDE: psicanálise e cultura. "Cultura", Vol. 31, No. 46, 2008. Sociedade Brasileira de Psicanálise de São Paulo. ISSN 0101-3106, p. 104-107.

. Centros de Referência - espaços de moradia transitória e reinserção para a população de rua na cidade de São Paulo. [Trabalho Final de Graduação, 69 p., orientação da Prof. Dra. Regina P. Meyer]. Faculdade de Arquitetura e Urbanismo da Universidade de São Paulo, FAU/USP, São Paulo, 2000.

SCHOR, Silvia M.; ARTES, Rinaldo. Primeiro Censo dos Moradores de Rua da Cidade de São Paulo: Procedimentos Metodológicos e Resultados. Revista de Economia Aplicada, Dez. 2001.

Disponível em:

$<$ http://pvalls.ibmec.br/seminariosIbmec/MoradoresdeRua.pdf\#search=\%22c enso\%20fipe\%20sas\%22>

SCHOR, Silvia M.; VIEIRA, Maria Antonieta da Costa. Principais resultados do Censo da população em situação de rua da cidade de São Paulo, 2009. Faculdade de Economia, Administração e Contabilidade da Universidade de São Paulo e FIPE - Fundação Instituto de Pesquisas Econômicas, 2009.

SEN, Amartya. Desenvolvimento como liberdade. São Paulo, Ed. Companhia das Letras, 2010.

Artigos em jornais e periódicos:

EM MEIO à pandemia do novo coronavírus, cresce o número de moradores de rua no Rio. Jornal Extra, 18 jun.2020. Disponível em:

$<$ https://extra.globo.com/noticias/rio/em-meio-pandemia-do-novocoronavirus-cresce-numero-de-moradores-de-rua-no-rio-24485324.html >

JEUDY, Henri-Pierre. Novas maneiras de 'pensar o habitar' - entrevistado por SANTOS, Maria Cecília Loschiavo dos. Jornal O Estado de São Paulo, São Paulo, 15 jun. 2000. Caderno 2.

KEHDY, Sergio. As perdas narcísicas com a pandemia. SPRJ Sociedade Psicanalítica do Rio de Janeiro, FEBRAPSI Federação Brasileira de Psicanálise. 27 jun. 2020. Webinar: Disponível em:

$<$ https://www.youtube.com/watch?v=lhgGGbDt7ho\&feature=youtu.be $>$

LARA, Wallace. Número de sem-teto nas ruas aumenta em SP durante a pandemia, dizem serviços de atendimento voluntário da cidade. Jornal G1 Globo. 29 mai.2020 . Disponível em:

$<$ https://g1.globo.com/sp/sao-paulo/noticia/2020/05/29/numero-de-semteto-nas-ruas-aumenta-em-sp-durante-a-pandemia-dizem-servicos-deatendimento-voluntario-da-cidade.ghtml >

LIMA, Juliana Domingos de; CHARLEAUX, João Paulo. Quais as medidas para a população de rua na pandemia. Jornal NEXO, 28 mar. 2020. Disponível em: $<$ https://www.nexojornal.com.br/expresso/2020/03/28/Quais-as-medidaspara-a-popula\% $\mathrm{C}_{3} \% \mathrm{~A} 7 \% \mathrm{C}_{3} \% \mathrm{~A} 30-$ de-rua-na-pandemia $>$

PAULUZE, Thaiza. Recenseadores contestam números do censo de moradores de rua divulgado pela gestão Covas. Jornal Folha de São Paulo. 31 jan.2020 Disponível em: 
<https://www1.folha.uol.com.br/cotidiano/2020/01/recenseadorescontestam-numeros-do-censo-de-moradores-de-rua-divulgado-pela-gestaocovas.shtml>

POPULAÇÃO DE rua na cidade de SP aumenta 53\% em 4 anos e chega a 24 mil pessoas. Jornal G1 SP e TV Globo, São Paulo, 30 jan. 2020

Disponível em:

$<$ https://g1.globo.com/sp/sao-paulo/noticia/2020/o1/30/populacao-de-rua-

na-cidade-de-sp-chega-a-mais-de-24-mil-pessoas-maior-numero-desde2009.ghtml>

PREFEITURA DE São Paulo divulga Censo da População em Situação de Rua 2019. 31 jan. 2020. Disponível em:

$<$ https://www.prefeitura.sp.gov.br/cidade/secretarias/assistencia social/obser vatorio social/pesquisas/index.php? $\mathrm{p}=18626>$

SCHOR, Silvia. É utopia pretender impedir que surjam moradores de rua. Jornal O Estado de São Paulo, São Paulo, o1 jun. 2010. Caderno Cidades / Metrópole, p. $\mathrm{C} 5$.

Disponível em:

$<$ http://www.estadao.com.br/estadaodehoje/20100601/not imp559677,0.php

$>$

Mapas:

Governo do Estado de são Paulo, Secretaria de Estado dos Transportes Metropolitanos. PITU 2020 - Plano Integrado de Transportes Urbanos para 2020: Síntese. São Paulo, jun. 1999.

Secretaria das Finanças - SF - TPCL 1999/SEMPLA-DEINFO e SPTRans - PMSP. São Paulo City Land Usage Map, Brazil 1999.

Disponível em:

$<$ http://www.zonu.com/brazil maps/Sao Paulo City Land Usage Map Bra zil 2.htm>

Acesso em: mai. 2010.

Secretaria das Finanças / Departamento de Rendas Imobiliárias - TPCL 2008. Uso do Solo Predominante - Subprefeituras do Município de São Paulo 2008. Elaboração: Secretaria Municipal de Desenvolvimento Urbano - SMDU / Departamento de Estatística e Produção de Informação - Dipro.

Disponível em:

$<$ http://sempla.prefeitura.sp.gov.br/infocidade/mapas/17 uso do solo predo minante 2008 2008 4.pdf $>$. Acesso em: jun. 2010. 